\title{
Gender Differences in HIVIAIDS Knowledge/Awareness among Adventist University Students in Arusha, Tanzania
}

\author{
Tuntufye Selemani Mwamwenda
}

\author{
Nelson Mandela Metropolitan University, 50 Holzner Road, Pinetown 3610, South Africa \\ tsmwamwenda@yahoo.com
}

\section{Doi:10.5901/mjss.2014.v5n27p726}

\begin{abstract}
The objective of this study was to assess university students' knowledge gender differences regarding HIVIAIDS at an Adventist institution in Arusha, Tanzania. This was undertaken on the ground that knowing about HIV/AIDS is one of the main ways by which the formidable disease can be controlled. The sample comprised 97 male (49) and female (48) participants who were administered an HIVIAIDS questionnaire consisting of 15 questions/statements. The data analysis comprised frequency, percentage, chi-square and level of probability. The results showed that on the basis of knowledgeability participants fell under those who scored high followed by those who were above average, average and below average. Similarly on the basis of gender differences, there were two categories, namely in a couple of questions, female participants performed better than their counterparts. In the second category, there was parity of genders, as their performance was equally good or unsatisfactory. In view of HIVIAIDS misconceptions and gender differences observed, it was concluded that the HIVIAIDS knowledge students commanded was not sufficient to lead to reduction in HIVIAIDS transmission. Thus calling for more public HIVIAIDS education in institutions of higher learning in Tanzania.
\end{abstract}

Keywords: University students and HIVIAIDS, HIVIAIDS knowledge/awareness, living with HIV/AIDS, gender differences Adventists, pandemic, inadequate HIVIAIDS knowledge.

\section{Introduction}

The number of women affected and infected by HIVIAIDS constitutes the majority worldwide (Paul, Majundarm AkhtarDanash, Bobin and Sherifali, 2013). The majority of those at greatest HIVIAIDS risk comprise those aged 16-30 years. Burgoya and Drumond (2008) report that comparatively, women in Africa are more affected with HIVIAIDS than is the case with their counterpart the men.

The reasons for such gender difference are many and are as follows: poorly educated, those with rural background, those who are economically dependent on men; taboo imposed on them by their culture regarding discussion based on sexual matters and health, submissive aspect in relationship with men; men dominant role in sexual decision making. All these factors contribute to women being less informed about HIVIAIDS.

According to Gahagan (2012) her investigation in Canada indicates that there is an increase in the number of women contracting HIVIAIDS which constitutes the reason for further investigation into gender inequality in the contraction of HIVIAIDS. She goes on point out many societies place the gender role of women in a position which makes it rather difficult for women to protect themselves against HIVIAIDS transmission. For examples, making it difficult to practice safer sex and being unable to avail themselves with HIV prevention services; women have less access to education, income, employment. In the long run these hold the women's limitations in their negotiation for safe sex and access to prevention to available prevention services

\section{Literature Review}

According to research findings, there exists a dichotomy in the HIVIAIDS knowledge genderly. In a sample of 126 female and 101 male university students in Ethiopia who were administered an HIVIAIDS questionnaire, there was no gender difference in the scores obtained by male and female participants. In this regard, Paul et al. (2013) argue that there is deficit of HIVIAIDS knowledge among secondary and university students. Similarly, there is less use of precaution, when young people engage in sexual activity. In a study of high school students, there was only 41 per cent female and 44 per cent male respondents who were adequately knowledgeable on HIVIAIDS. In a nationwide study, only male 28.9 and 15.8 female participants were adequately versed in HIVIAIDS knowledge. Lack of parity in HIVIAIDS gender knowledge 
was attributed to various factors, namely: 1) contextual gender roles; 2) lower rates of literacy; 3) and lower school enrolment among women, when compared to male participants

Addressing HIVIAIDS in Tanzania institutions of higher education poses a serious challenge based on the following factors (African Medical Research Foundation (AMREF, 2010): 1) Little is known about the vulnerability, prevalence, impact as well as situation of HIVIAIDS in most higher education institutions in Tanzania; 2) There is a tendency on the part of senior academics to presumptuously assume that, matters patterning to HIVIAIDS fall under the domain of junior academics and students; 3) HIVIAIDS is given rather low priority, when it comes to allocation of resources (human, financial, time and space). As a result, there is constraint on integrated and comprehensive institutional HIV and AIDS programmes.

In a sample of six universities selected cross-sectionally based on geographical location, ownership 9public, private or faith-based.

There were 2,426 students who constituted respondents. Data was collected on the basis of social survey, interviews and focus discussion groups

Those who believed in dual methods of the HIVIAIDS prevention was low as it fell short of 50 per cent for both males (47\%) and females (44\%). The dual method means reduction of being susceptible to HIVIAIDS infection by being faithful to an uninfected partner and using condom simultaneously. Otherwise over 70 per cent of males and females held the view that use of condom reduces the chances of contracting HIVIAIDS. There was similar per cent (50\%) who believed that having one faithful partner who is uninfected protects one from being HIVIAIDS infected.

Most common misconceptions were contracting HIVIAIDS through mosquito bites, and sharing eating utensils with an HIVIAIDS infected person. Other misconception were: shaking hands with an infected person, sharing toilet with an infected person. There was nevertheless gender difference in rejection of misconception 45 per cent males nd 47 per cent females.

In comprehensive knowledge of HIVIAIDS results showed significant difference within universities regarding comprehensive knowledge about HIVIAIDS. By comprehensive HIVIAIDS knowledge is meant consistent use of condom, having one faithful partner knowledge that one cannot be identified un infected on the basis of appearance,3) rejecting two commonest misconceptions namely mosquito bites and shaking hands with an HIVIAIDS person.

On the basis of this criterion, there were, nevertheless, significant gender differences observed. At one university males students had a significant difference, whereas at another university females knowledge as statistically significant more than was the case in the remaining four participating universities. On the basis of age, males aged 40-44 and female students of similar age were observed to be more knowledgeable than their corresponding counterparts in the other groups. On the basis of year of study, first year male students were les knowledgeable than any other year of study. whereas second year female students were less knowledgeable than any other year of study. The results based on year happen to be more significant for male students than those of female students were not statistically significant.

Mwamwenda (2014) examined gender differences in the belief that adolescents are not at risk of HIVIAIDS infection. The investigation comprised 366 male and female participants selected from Kenya, South Africa and Tanzania. There were statistically significant gender differences in the belief that adolescents were not susceptible to HIVIAIDS transmission. In Tanzania, men had a knowledge score of 76.7 per cent compared to a sore of 73.2 per cent for women. Kenya male participants had a score of 79.8 per cent, whereas women had a score of 80.6 per cent. For South Africa, men scored 77.4 per cent compared to 73.4 per cent for women. In all the three countries, the gender differences were statistically significant; with males in South Africa and Tanzania outperforming females, whereas in Kenya the female respondents outperformed male respondents.

In Nigeria, Aluede, Imhonde, Maliki and Alutu (2005) assessed university students level of knowledge about HIVIAIDS with a sample comprising 900 undergraduate students consisting of 520 male and 380 female students. The results showed that the respondents had a highly favourable knowledge regarding HIVIAIDS. Furthermore, the results showed a statistically significant gender differences in HIVIAIDS knowledge with male students showing higher knowledge of HIVIAIDs than was the case with female participants.

According to Gahagan (2012) her investigation in Canada indicates that there is an increase in the number of women contracting HIVIAIDS which constitutes the reason for further investigation into gender inequality in the contraction of HIVIAIDS. She goes on point out many societies place the gender role of women in a position which makes it rather difficult for women to protect themselves against HIVIAIDS transmission. For examples, making it difficult to practice safer sex and being unable to avail themselves with HIV prevention services; women have less access to education, income, employment. In the long run these hold the women's limitations in their negotiation for safe sex and access to prevention to available prevention services

Terry, Mhloys, Masavaure and Adlis (2005) investigated gender differences in HIVIAIDS knowledge among 933 
university students in Zimbabwe on the basis of cultural, sociological and economic variables. Male participants expressed the views that: they had the right to dominate women, and that they were the ones to decide the use of condom. In contrast, the women participants acknowledged the gender cultural attitude towards women and went further by asserting their support for women's rights to sexual activity.

In a similar investigation, Ugbona, Kooffeh and Nwauche (2011) examined gender differences in students' knowledge of HIVIAIDS on a sample of 1748 secondary school students aged 12-19 years of ge drawn from 12 schools. Their knowledge was high as it stood at $80 \%$. However, there was no gender difference in their knowledge of HIVIAIDS

Montosh, Asagwara and Meriamu (2011) carried out a study of 2399 university students in Lagos, Nigeria, in which participants had a moderate knowledge of HIVIAIDS. It was also reported that female participants were predisposed to contracting HIVIAIDS, because of their engaging in high risk sexual behaviour for financial reasons. In terms of gender difference in HIVIAIDS, no difference of significance was observed.

According to a cross-national survey carried out in Ethiopia, Mali and Nigeria 97-98\% of men had a knowledge of HIVIAIDS compared to $86-90 \%$ for women who were just as knowledgeable. Similar survey carried out in Kenya and Madagascar showed gender difference showing that men showed more than women. The study carried out in Rwanda, however, showed no gender difference in HIV difference in HIVIAIDS between females and males.

Durojaiye (2011) refers to HIVIAIDS is one of the most dreaded and devastating diseases in human recent history. It is therefore argued that behaviour change on the part of men and women presents the most effective way of controlling transmission and infection of HIVIAIDS. In a sample of 315 students consisting of both married and single participants. Their knowledge of HIVIAIDS was very high. It was observed that participants who were married were more knowledgeable than those who were single. On the other hand, a statistical analysis the gender differences between male and female participants were on-significant.

In Malaysia, Wong, Chin, Low and Jaafar (2008) young adults' knowledge of HIVIAIDS was moderate given that they had of 4.6 out of 17 points. The majority of participants knew what HIVIAIDS was about. There were gender differences with female participants showing higher scores than male participants. Mundingayi, Lutala and Mupenda (2011) in Kinshasha, Democratic Republic of Congo, advance the argument that knowledge has a prominent role as predictor of HIV risk behaviour. As a result of IVIAIDS knowledge, the following are likely to hold true: deferred onset of sexual relationship; consistent use of preventive measures during sexual intercourse; reduction in the number of sexual partners; increase in relating to HIVIAIDS infected persons positively. Their investigation of HIVIAIDS knowledge was high for both female and male participants. As such, there

In a comprehensive response to the HIVIAIDS epidemic in Jamaica, Figueroa, Duncan, Byfield, Harvey, Gere, Hylton, Kong, Hamer, Williams, Carrington and Braithwaite (2008) describe HIVIAIDS rates in Jamaica as being higher among than in women which is attributed to : men's heterosexual males behaviour involving high sexual risk behaviour, given that they have multiple partners, involvement in commercial sex and HIV rates being high among men having sex with men. The reports further points out that, while HIVIAIDS infection among women is on the decline, for men it is on the increase. This is attributed to women practicing safer sex than men; assessing HIV testing and continued high rates of HIV among MSM (Figuerona et al., 2008). It is nevertheless important to note that among adolescents, HIVIAIDS transmission is immensely dramatic. With adolescents the rates of HIVIAIDS among females is three times higher than males (Figuerona et al., 2008).

In Nigeria, Oladokun, Jiboye, and Akichemi (2010) conducted an investigation on in-school students' HIV awareness and sexual behaviour. They preamble their presentation by pointing out that knowledge about HIV and sexual practices plays an important role in the prevention of HIVAIDS transmission. This served as motivation for pursuing the assessment of school adolescents. The results were that based on 1045 participants with a distribution of 501 males and 544 females, $02 \%$ had a good knowledge off HIVIAIDS. Statistical analysis of gender difference showed that their knowledge was at par, as there was no statistically significant difference between male and female respondents.

The preceding review of literature served as a motivation and backdrop for undertaking the present investigation, with the purposes of finding out the HIVIAIDS level of knowledge and whether such knowledge would significantly differ genderly, as well as whether such findings would either affirm or deaffirm what other researchers have reported, as presented in the review of literature.

\section{Method}

\subsection{Sample}

The sample of the study comprised 97 university students pursuing their studies at an Adventist University in Arusha at 
the foot of Mount Kilimanjaro, Tanzania, the highest mountain in Africa and only second to Mount Everest in Nepal, the highest mountain in the world. Of the total participants, there were 48 females, whose age ranged from 18 to 47 years, and had a mean of 26.9 years with a standard deviation of 7.9. Males' age ranged from 20 to 54 years with a mean of 30 and a standard deviation of 9.2. The majority of participants were young and single, whereas a few were married which was applicable to both men and women.

\subsection{Questionnaire}

The respondents were administered an HIVIAIDS questionnaire of 15 statements/questions to which they were asked to tick the most correct response on the basis of the three options provided, which were "Yes", "No" "Do not know". The questionnaire was administered by one of the academic member of staff at the University that, the researcher happens to have known for many years. All protocol observed, necessary permission was sought and granted from the senior management of the University. Similar consent was solicited from participants.

For confidentiality purpose, respondents were asked not to write their names on the questionnaire. For biographical information, they were requested to indicate their date of birth and gender in the space provided on the questionnaire.

\section{Results}

Table 1 shows the results based on: frequencies, percentage, chi-square and level of probability. The response to whether a person would contract HIVIAIDS, as a result of drinking water from the same glass with an HIVIAIDS infected person was rejected by $69 \%$ male and $71 \%$ female respondents. Both scores were above average. The gender difference was not statistically significant based on a chi-square test. When asked whether kissing an infected person would

Table 1: Participants' Frequencies, Percentage, Chi-squares and Probability

$\mathrm{N}=97$

\begin{tabular}{|c|c|c|c|c|c|c|c|}
\hline \multirow{2}{*}{ No. } & \multirow{2}{*}{ Statement } & \multicolumn{2}{|c|}{ Males } & \multicolumn{2}{|c|}{ Females } & \multirow[b]{2}{*}{$x^{2}$} & \multirow[b]{2}{*}{$\mathbf{P}$} \\
\hline & & Freq. & $\%$ & Freq. & $\%$ & & \\
\hline 1 & Drinking from the same cup used by AIDS person & 34 & 69 & 34 & 71 & 0.024 & ns \\
\hline 2 & Kissing a person who has AIDS & 30 & 61 & 32 & 67 & 0.311 & ns \\
\hline 3 & Taking care of person who has AIDS & 20 & 41 & 19 & 40 & 0.533 & ns \\
\hline 4 & Receiving blood from a person who has AIDS & 26 & 53 & 25 & 52 & 0.009 & ns \\
\hline 5 & Having sex with a person who has AIDS & 24 & 51 & 24 & 50 & 0.096 & $\mathrm{~s}$ \\
\hline 6 & AIDS is God's punishment for sexual sin & 31 & 63 & 32 & 67 & 0.123 & ns \\
\hline 7 & Africans have a cure for AIDS & 40 & 82 & 40 & 83 & 0.049 & ns \\
\hline 8 & Research has finally found the cure for AIDS & 27 & 55 & 35 & 73 & 3.34 & $0.05^{*}$ \\
\hline 9 & There is no way I will be infected with AIDS & 14 & 29 & 10 & 21 & 1.472 & ns \\
\hline 10 & Would you sit next to a person who has AIDS? & 44 & 90 & 39 & 81 & 1.434 & ns \\
\hline 11 & People who have AIDS are responsible for it & 10 & 20 & 38 & 80 & 2.407 & $0.10^{*}$ \\
\hline 12 & AIDS children should attend school with others & 45 & 92 & 46 & 94 & 0.667 & ns \\
\hline 13 & Would you accept being tested for AIDS? & 39 & 80 & 43 & 90 & 1.852 & ns \\
\hline 14 & Are you careful in your relationship with boys/girls to avoid getting AIDS? & 46 & 94 & 47 & 98 & 1.001 & ns \\
\hline 15 & There is no such thing as AIDS & 39 & 80 & 35 & 73 & 0.597 & ns \\
\hline
\end{tabular}

ns= nonsignificant; * Significant

Whether HIVIAIDS infected children should attend school with uninfected children, the majority of participants (96\%) thought that was the right thing to do. Whether kissing an HIVIAIDS would lead to contracting HIVIAIDS, $61 \%$ of male and $67 \%$ female students rejected this hypothesis. The scores for the two genders were above average and there was significant gender difference (0.05) in favour of female participants.

Whether one would be HIVIAIDS infected, as a result of taking care of an HIVIAIDS person was also rejected by $41 \%$, male and $40 \%$ female participants as a source of transmission. Both male and female participants scored below average which was statistically significant (0.05), meaning that more respondents believed that one would contract HIVIAIDS as a result of caring for a person living with AIDS. This is a misconception of HIVIAIDS. 
Receiving blood from an HIVIAIDS person was acknowledged as leading to infection by $53 \%$ and $52 \%$ female students. Both scores fell under the average performance category. This was accepted as one of the ways of being infected with HIVIAIDS. There was no gender difference. Being infected by having sex with an infected person was acknowledged by $51 \%$ male and $50 \%$ female of the participants.

As regards HIVIAIDS being God's punishment was rejected by $63 \%$ male and $67 \%$ female of the respondents. The scores were comparable and therefore there was no gender difference. Whether Africans have a cure for AIDS was rejected by $82 \%$ male and 83 female students. Both scores fell under the category being very high. No gender difference was observed as participants were equally knowledgeable about HIVIAIDS. The majority of female participants (73\%) thought that researchers have not identified the cure for HIVIAIDS, compared to 55\% male participants who thought the same way. The score of female participants fell under high, whereas that of males was average. The gender difference was significant $(0.05)$ in favour of female respondents.

Whether participants were vulnerable to being HIVIAIDS infected was rejected by $71 \%$ male and $79 \%$ female of the respondents, which was incorrect. Both correct scores fell under very low, and there was no gender difference. Whether they would agree to sit next to an HIVIAIDS infected person, $90 \%$ male respondents did not think there was a problem with such behaviour, compared to $81 \%$ female respondents. The two scores were very high and gender difference was not significant. In response to the statement that HIVIAIDS persons should be held responsible for contracting such disease, the majority of female respondents (80\%), whereas there only $20 \%$ of the males who felt thus. The gender difference was statistically significant $(0.10)$ in favour of female respondents, taking the position that infected persons should be blamed for their disease.

Whether HIVIAIDS infected children should attend school with uninfected children, the majority of both gender participants (92\% men and $83 \%$ women)) thought that was the right thing to do. Both scores were very high and the gender difference was not statistically significant. Whether participants would be ready to be tested for HIVIAIDS, $94 \%$ males responded positively which was similar to $98 \%$ females giving a similar response. The scores for both genders were very high and there was no sex difference in their performance.

In response to whether participants were careful in their relationships with members of the opposite sex, for the purpose of guarding against being HIVIAIDS infected, 94\% male participants were in agreement with the statement. Similar response was applicable to $98 \%$ female participants. The scores were very high and there was no significant gender difference. In response to whether there is no such thing as AIDS, $80 \%$ male participants rejected the statement, while $73 \%$ female participants were in agreement with their counterparts. While the male score was very high, that of females was high. There was no significant gender difference. The statement that there is no such thing as AIDS was rejected by $80 \%$ male and $73 \%$ female participants. The gender difference was not significant.

\section{Discussion}

The purpose of this investigation was of twofold, namely to assess the HIVIAIDS knowledge of university students at a faith-based (religious) institution in Arusha, Tanzania. The second objective was to examine the gender differences in the performance of participants comprising 49 male and 48 female respondents. The underlying motivation was the established fact that, there is no known cure for HIVIAIDS and that, in view of this knowledge of HIVIAIDS is the only option available in the control of HIVIAIDS transmission. Such a stance is taken on the understanding that being knowledgeable about HIVIAIDS will empower potential victims to guard against being HIVIAIDS infected. Oladokun et al. (2010) argue that knowledge about HIVIAIDS plays an important role in the prevention of HIVAIDS transmission

The findings of the data analysis showed that participants' performance fell into three categories comprising those who per formed very highly which ranged from $80 \%$ and above; those who performed highly with the range of $70 \%$ s; the third category was above average whose scored fell in the $60 \%$ s; followed by average scoring within $50 \%$ s; the lowest category was those who scored below 50\%. In terms of gender difference, in some statements/questions female participants performed better than male participants. In others male participants did not outperform female participants to a significant level. In the third category, the set of participants were at par in their performance. The parity was of dual nature in as much this held true in two directions. In terms of performing well this held true for both genders. The other direction was that for those who performed unsatisfactorily, it applied to both genders. Mwamwenda (2014) examined gender differences in the belief that adolescents are not at risk of HIVIAIDS infection. The investigation comprised 366 male and female participants selected from Kenya, South Africa and Tanzania. There were statistically significant gender differences in the belief that adolescents were not susceptible to HIVIAIDS transmission. These findings are in agreement with what has been reported in the present investigation.

Similarly, Alued et al. (2005) reported similar findings. Part of the findings of the present study showed that there 
was parity in terms of gender difference where females and males were equally knowledgeable or un unknowledgeable in their HIVIAIDS awareness. This confirms what similar studies have reported (Durojaiye, 2011; Mantosh et al; Paul et al., 2013; Ugbona et al. 2011). In terms of gender differences in which case either one of the gender performing better than the other, such findings have support from similar investigations in various parts of the world (AMREF, 2013; Aluede et al. 2005; Wong et al. 2008; Mwamwenda, 2014). This held true only for female respondents outperforming their counterparts.

\section{Conclusion}

In keeping with the objective of the investigation, it is clear that the participants were familiar with the HIVIAIDS knowledge considered essential for guarding against contracting HIVIAIDS. Similarly, the gender differences in the knowledge of HIVIAIDS was indicative of familiarity with the subject matter. However, it would not be correct to conclude that, the participants know all that is to be known about HIVIAIDS.

The number of HIVIAIDS misconceptions manifest by both female and male respondents are a clear evidence that more must be done in the provision of HIVIAIDS public education. Even where it is thought that enough public education has provided, there is need to ensure that the situation is monitored and reconsolidated on a regular basis. Short of this, we will be faced with the peril of losing the battle to the scourge of HIVIAIDS, which has left (those living with HIVIAIDS) and claimed millions of Africans in Sub-Saharan Africa.

\section{References}

Alulede, O., Imhonde, H., Maliki, A. \& Alutu, A. (2005). Assessing Nigerian university students' knowledge about HIVIAIDS. Journal of Social Sciences, 11(3), 207-213.

Burgoya, A. D. And Drummond, P. (2008). Knowledge of HIV and AIDS in women in Sub-Saharan Africa. African Journal of Reproductive Health, 12(2), 14-31.

Durojaiye, O. (2011). Knowledge, attitude and practice of HICVIAIDS: Behavior change among tertiary education students in Lagos, Nigeria. Annals of Tropical Medicine and Public Health, 41(1), 18-24.

East African Community/African Medical Research Foundation, (2010). HIV sero-behavioural study in six universities in Tanzania: Final Report. Swedish International Development Agency.

Figueroa, J. P., Duncan, J., ayfield, L., Harvey, K., Gebre, Y., Hylton-Kong, T., Hamer, F., Williams, E., Carrington, D. And Braithwaite, A. R. (2008). A comprehensive response to the HIVIAIDS epidemic in Jamaica: $R$ review of the past 20 years risk behaviours: Multiple sexual partners, history of STI, commercial sex, crack/cocaine. West Indian Medical Journal, 57/6

Gahagan, J. (2012). Gender matters in HIV prevention. Online at:www.catie.ca/en/pf/spring-2012/gender matters-hiv-prevention

Montoh, S. O., Asagwara, C. G. And Meriamu, U. H. (2011). Male gender roles and sexuality: Implication for university girls HIVIAIDS awareness in a Nigerian university. Journal of International Women's Studies, 8(4), 148-152.

Mundingayi, A., Lutala, P. And Mupenda, B. (2011). HIV knowledge and sexual behaviour among street adolescents in rehabilitation centres in Kishasha, DRC: Gender differences. The African Medical Journal, 10(23).

Mwamwenda, T. S. (2014). African university adolescents' gender differences in HIVIAIDS vulnerability. Journal of AIDS and HIV Research, 6(2), 39-43.

Paul, M., Majundar, B., Akhtar-Danash, N., Boblin, S. \& Sherifali, D.(2013). Ist annual interdisciplinary conference, AHC 601-609, April 24-26.

Oladokun, R. E., Jiboye, J. And Akichemi, J. O. (2010). HIV awareness and sexual behaviour among in-school students in North-Central Nigeria. Review in Infection, 1(2), 94-99.

Terry, P. E. Mhloys, M., Masavaure, T. and Adlis, S. (2005). Gender equity and HIVIAIDS prevention: Comparing gender differences in sexual practices and beliefs among Zimbabwe university students. International Quarterly of Community Helth Education, 24(1), 29-43.

Ugbona, H. A., Kooffel, M. E. And Nwauche, A. A. (2011). Gender differences in students' knowledge of HIVIAIDS in the Niger Delta, Nigeria. Journal of Clinical Medicine and Research, 31(1), 20-22.

Wong, L., Chin, C. L., Low, W. And Jaafar, K. (2008). HIVIAIDS-related knowledge among Malaysian young adults: Findings from a nation-wide survey. The Medscape Journal of Medicine, 10(6), 148. 